Revista De Arquitectura

Editado por la Facultad de Arquitectura y Urbanismo de la Universidad de Chile

Dirección: Campus Andrés Bello

Portugal $N^{\circ} 84$, Santiago de Chile Teléfono: (56-2) 9783081

revista@uchile.cl

Rector: Luis Riveros C.

Decano: Julio Chesta P.

Vicedecano: Leopoldo Dominichetti C.

Representante Legal: Rector Universidad de Chile

Gerencia: Dirección Económica y Administrativa F.A.U.

Director: Constantino Mawromatis P.

Consejo Editorial: Luis Goldsack J., Alberto Gurovich W., Sofía Letelier P., Leopoldo Prat V.

Editores: Pablo Cid B., Rubén González A., Diego Vallejos 0.

Coordinadora Área Docente: Cecilia Wolff C.

Concepto Gráfico: Hugo Reyes G. Asesor Fotográfico: Guy Wenborne H.

Equipo Colaboradores: Elisabeth Ávalos, David Campos, Alejandra Celedón, José Contreras, Felipe Corvalán, José Maldonado, Paola Mora, Daniela Salvo, Carolina Sepúlveda

Corresponsales: Sebastián Bravo (Buenos Aires), Carolina Briones (Londres), Pietro Clandestino (Venecia), José Contreras (Atlanta), Emilio Cuneo (Londres), Loreto Flores (Londres) Ernesto López (Londres), Darío Oyarzún (Roma), Miguel Vitale (Santa Fe)

Traducciones: Pablo Cid, José Contreras, Sofía Mawromatis, Ute Rehfeld,

Daniela Salvo, Macó Seni,

Diego Vallejos, Cecilia Wolff

Por su ayuda desinteresada y enérgico entusiasmo agradecemos a María Isabel Pavez y Fernán Meza

Agradecemos la colaboración de Miriam Astudillo, Margarita Contreras, Sara Hevia, Alicia Madrid, Angélica Ortiz Nieves Riquelme, Claudio Soto, Pedro Soza y Sergio Vásquez

Diseño e impresión:

versión I producciones gráficas Itda.

Dirección de Arte:

Salvador Verdejo V.

Teléfono [56-2] 2698489

version@entelchile.net

\section{Carta del Decano}

\section{Letter from the Dean}

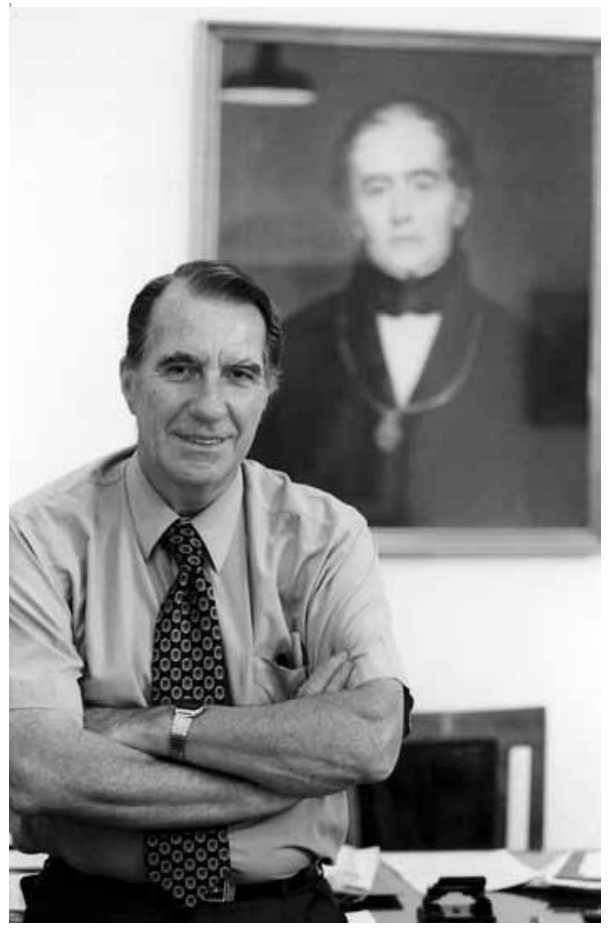




\section{Bienvenidos a una nueva etapa}

La Facultad de Arquitectura y Urbanismo de la Universidad de Chile inaugura, con este número, una nueva etapa de la Revista De Arquitectura, vehículo para la expresión del pensamiento y avances que, en este ámbito, realizan sus diferentes líneas de desarrollo y que la consolidan como gran centro de estudios, con tradición y actualidad. Fue en sus aulas donde se impartió por vez primera en Chile el Curso de Arquitectura, ya en 1849, pocos años después de la Independencia. Hoy, con 5 departamentos de desarrollo disciplinar y 3 institutos de investigación de problemas nacionales, ostenta un reconocimiento, nacional e internacional, a la docencia de pre y posgrado que imparte y a sus demás funciones universitarias. El compromiso de la Universidad de Chile con el país y su desarrollo, con valores de participación, tolerancia, transparencia y excelencia académica y profesional, dibujan el marco en que esta Facultad desarrolla sus múltiples actividades dando sustento al espíritu crítico, de crítica reflexiva y respetuosa, que se reflejará en este medio. Desde este hermoso Campus, situado en el corazón de Santiago, saludo el esfuerzo por impulsar este medio y manifiesto que sus páginas y sus puertas están abiertas para quienes se interesen por el diseño del entorno con calidad, por los valores ciudadanos y por las inquietudes académicas de la disciplina.

La revista que ahora está en vuestras manos, cumple un importante papel como ventana hacia y desde esta Facultad, que se suma al que cumplen hace un tiempo la Revista INVI, la Revista de Urbanismo y la Revista de Investigaciones Geográficas, junto a nuestro renovado sitio web "www.uchilefau.cl" que articula esta comunidad universitaria con los multimedios.

Pero una revista no es más que un medio para la expresión de lo que se piensa y de lo que se avanza en el conocimiento.

Estoy cierto que con la participación entusiasta de académicos, estudiantes y colaboradores, la revista en su nueva etapa, se consolidará en el tiempo y llegue a convertirse en un importante aliado de nuestro proyecto académico y educativo.

Los invito a hacerse parte de él.

Julio Chesta P.

Decano Facultad de Arquitectura y Urbanismo, Universidad de Chile 